\title{
Correction to: The Nature of Intelligence Requirements, Internal Roles and Relations in the Twenty-First Century
}

Ingeborg Guldvik Grongstad and Kenneth L. Lasoen

\section{Correction to:}

T. Røseth, J. M. Weaver (eds.), Intelligence Relations in the 21st Century, https://doi.org/10.1007/978-3-030-34004-9_2

It was confirmed that the chapter needed major edits. The substance within needed re-work and the references needed to be more solid along with in-text citations. The linkages between the concepts were required to make sure that it was communicated most effectively. The abstract had

The updated version of this chapter can be found at https://doi.org/10.1007/978-3-030-34004-9_2

I. G. Grongstad ( $\square)$

Oslo, Norway

K. L. Lasoen

Political Science Department, University of Antwerp, Antwerp, Belgium History Department, Ghent University, Ghent, Belgium

(C) The Author(s) 2020

T. Røseth, J. M. Weaver (eds.), Intelligence Relations in the 21st Century, https://doi.org/10.1007/978-3-030-34004-9_8 
C2 CORRECTION TO: THE NATURE OF INTELLIGENCE REQUIREMENTS...

been revised for better understanding. A co-author was also included to this chapter. Kenneth is a scholar in this field; he was involved in revising and analyzing the Manuscript. All of the above mentioned corrections have been updated in this revised version. 